\title{
René Descartes y su influencia en el siglo XVII mexicano
}

\section{Laura Benítez}

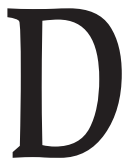

\section{escartes y la vía de reflexión epistemológica}

Al inicio, como una pequeña senda poco transitada, la vía de reflexión epistemológica comenzó a labrarse en la baja Edad Media, cuando la actitud crítica de Nicolás de Cusa rechazó para el hombre la posibilidad del conocimiento de la quididad. Para el cusano, el entendimiento no puede alcanzar las esencias que sólo Dios puede conocer. Propio de la mente humana es medir y comparar. Lentamente, en la nueva vía reflexiva, los afanes se vuelcan hacia las operaciones de la mente que, en un inicio, se distinguen con dificultad de sus contenidos. Obra de los más importantes filósofos modernos, quienes ensancharon esta vía de reflexión, fue justamente el intentar aclarar los diversos aspectos de los contenidos y estructuras mentales.

En la perspectiva del humanismo renacentista, y su peculiar idea del hombre como microcosmos, surge la diferenciación del sujeto y el entorno. En efecto, el alma, en principio es capaz de reflejar el cosmos, y puede, según Ficino, engarzarlo a través de sus conceptos en una unidad.

Poco a poco, el entorno se convierte en mundo externo a la mente, al sujeto, al yo. Es sin duda Descartes, quien de manera fundamental contribuyó a la consolidación de la vía de reflexión epistemológica con su propuesta dualista,

Nota de la redacción: En 1996 se celebran los cuatrocientos años del nacimiento de René Descartes (1596-1650). La obra de Descartes es un punto de inflexión en la historia de la filosofía. Su legado -al decir del filósofo español Felipe Martínez Marzoa-, más que en un conjunto de conocimientos, reside en su consideración de la sabiduría como una actitud regida por principios. La doctora Laura Benítez trata en su texto -mínimo homenaje de Theoría al pensador de la duda metódica- de mostrar, entre otras cosas, cómo recogieron esta actitud dos de los intelectuales mexicanos más importantes del siglo XVII: Carlos de Sigüenza y Góngora y sor Juana Inés de la Cruz. 
la cual hace énfasis, por un lado, en la independencia del sujeto con respecto al universo material y, por otro, en la unidad del mundo como extensión cuantificable.

Es propio de la vía de reflexión epistemológica el no fundar el conocimiento ni en el sentido común ni en las meras ficciones especulativas. La crítica, en la nueva ciencia, sometió a examen tanto las versiones del mundo que los sentidos nos entregan, como las provenientes de las meras operaciones del entendimiento, de esta suerte, tanto los métodos, dentro del campo de la ciencia, como la reflexión metodológica, en el de la filosofía, se fueron desarrollando a la par que se ensanchaba el conocimiento del mundo.

Es pues manifiesto que, para la nueva filosofía, el mundo no ha dejado de interesar sino que este interés adquiere una nueva significación y lugar en la vía de reflexión epistemológica.

Para la crítica cartesiana no puede dejarse a la mera sensibilidad el conocimiento del mundo si se duda sobre la claridad y distinción de las ideas sensibles y se sostiene, además, que no son semejantes a lo que representan; pero, por otra parte, las teorías muy generales elaboradas por la mente no pueden extenderse con facilidad a la inmensa variedad de los fenómenos que experimentamos. ${ }^{1}$

\section{La vía de reflexión epistemológica y el dualismo cartesiano}

Como se anotó, dentro de la vía de reflexión epistemológica, el sujeto adquiere tal importancia que, si no posee la vis entitativa o creadora de Dios, quien al pensar pone los entes, sí posee, para Nicolás de Cusa, una vis assimilativa, que le hace creador de su mundo cultural a través de sus conceptos. Este punto de vista, aunado a las propuestas humanistas de la escuela florentina, del hombre como microcosmos, capaz de reflejar y enlazar la totalidad del universo, abre paso a la idea de un sujeto separado de aquél, con una naturaleza no fija, capaz de remontar el mundo natural y erigir, sobre él, su mundo, el mundo humano.

Todo ello sirvió de preámbulo a la propuesta de Descartes, de un sujeto no sólo independiente, sino totalmente diferente, ontológicamente, al mundo natural. Este "yo" se constituyó en el sujeto primario y fundante de la filosofía cartesiana.

No hay duda de que soy si me engaña [un ser engañador muy poderoso]

${ }^{1}$ Cf. René Descartes, Discours de la Méthode. Indiana-Londres, University of Notre Dame, 1994. 
y que me engañe tanto como quiera, no podrá jamás hacer que yo no sea en tanto yo piense que soy alguna cosa. De modo que después de haberlo pensado bien y haber examinado cuidadosamente todas las cosas, finalmente es necesario concluir y tener por constante que esta proposición: yo soy, yo existo, es necesariamente verdadera. ${ }^{2}$

Descartes estipula la existencia del pensamiento como una sustancia privilegiada, al menos en dos sentidos:

1) Por el acceso inmediato a sí mismo que el yo tiene, lo cual implica, naturalmente, no sólo la conciencia, sino cierta transparencia epistemológica. ${ }^{3}$

2) Porque el "yo" pensante o res cogitans, que es ontológicamente diferente de la res extensa, puesto que ninguna de las dos sustancias, según Descartes, comparte propiedades con la otra, no obstante, puede acceder a la estructura profunda del mundo, a su verdadera esencialidad, y conocer las leyes eternas que lo rigen universalmente, decretadas por Dios de una vez y para siempre.

Curiosamente, al acceder a sí mismo, el yo encuentra contenidos mentales, operaciones del alma, etcétera, pero también puede encontrar naturalezas simples, estructuras básicas que le revelan no sólo cómo es esencialmente el mundo (extensión) y sus modos generales (figura, tamaño, movimiento, disposición de las partes de materia qua extensión), sino que debe llegar a saber que este conocimiento está garantizado por la existencia de Dios, cuya idea le es innata, lo que le permite eliminar cualquier duda, aun sobre conocimientos aparentemente claros y distintos. ${ }^{4}$

En buena medida, este acceso del "yo" a las características y leyes fundamentales del universo, se debe a que Descartes estipula la existencia del mundo externo como un mundo homogéneo cuyo modo esencial es la extensión. Es decir, busca una reducción racional del mundo, un mundo inteligible capaz de

${ }^{2}$ R. Descartes, Oeuvres philosophiques. París, Editions Ganier Frères, t. II, 1967, p. 415 .

3 Dice Descartes en la "Segunda meditación": “[...] no puedo otorgarle mi juicio sino a las cosas que me son conocidas: reconocí que era, y busco qué soy yo, yo que he reconocido ser. Luego, es muy cierto que esta noción y conocimiento de mí mismo, tomada precisamente así, no depende de las cosas cuya existencia no me es todavía conocida [...]” (R. Descartes, op. cit., pp. 419-420.)

${ }^{4}$ En la "Quinta meditación", Descartes refiere: "Pero después de haber reconocido que hay un Dios, puesto que al mismo tiempo he reconocido también que todas las cosas dependen de él, y que no es engañador, y que inmediatamente después de esto he juzgado que todo lo que concibo clara y distintamente no puede dejar de ser verdadero, aun cuando yo no piense más en las razones por las cuales he juzgado esto como verdadero, con tal de que me acuerde haberlo comprendido clara y distintamente, no se me puede presentar ninguna razón contraria que me lo haga poner en duda; $y$ así, yo tendré de ello una ciencia verdadera y cierta". 
ser comprendido por la mente de manera clara y distinta. Sin embargo, hay que notar que, ontológicamente, la res extensa tiene una existencia independiente de la res cogitans, por lo cual Descartes es, en primera instancia un realista pero, la diferencia real que establece entre las dos sustancias, hace que, epistemológicamente, la conciencia no pueda acceder al mundo sino a través de sus ideas por lo que el realismo resulta indirecto.

En suma, tanto la separación del "yo" de entre las cosas del mundo, como la homogeneidad del universo, cuyos antecedentes más próximos se encuentran en los autores renacentistas, se constituyen, con las especificaciones antes mencionadas, en los principios filosóficos más importantes del sistema dualista cartesiano.

\section{Descartes y los dos grandes criollos del siglo XVII novohispano}

\section{La filosofía cartesiana y Carlos de Sigüenza y Góngora}

Don Carlos de Sigüenza y Góngora (1645-1700), constituye un punto de referencia obligado en el ámbito de la historia intelectual y científica de México. El año de 1672 marca el inicio de su productiva carrera de matemático, astrónomo, literato e historiador que le valió los títulos de erudito y polígrafo.

De la abundante obra de don Carlos, resaltan por su filiación a la nueva filosofía y en consecuencia a la nueva ciencia, La libra astronómica y filosófica que escribió en 1680, posterior al Manifiesto filosófico contra los cometas del mismo año.

En ambas obras puede percibirse su modernidad científica y filosófica en relación con el arduo problema de la disputa cometaria surgida ese año.

Es un hecho que don Carlos se dedicó a la actividad científica con manifiesta dilección, pero sobre todo le entusiasmaba el método de la nueva ciencia. En La libra menciona que la crítica es indispensable para el quehacer científico pues, en sus palabras, se necesita de "libertad filosófica" que nos permite librarnos de "perjudicados afectos" con el objeto de llegar al conocimiento científico: "Iré por diverso camino, que es el que me abre la filosofia, para llegar al término de la verdad". 5

Existen diversos textos tanto en el Manifiesto... como en La libra que muestran la preocupación de Sigüenza por el método, pero no desarrolló una reflexión metodológica ni mucho menos hizo realmente una propuesta

${ }^{5}$ Carlos de Sigüenza y Góngora, La libra astronómica y filosófica, presentación de José Gaos, ed. de Bernabé Navarro. México, Centro de Estudios Filosóficos, UnAM, 1959, p. 11, núm. 12. 
epistemológica amplia y propia. Más bien, siguiendo a los modernos, Sigüenza menciona que la mera retórica, la argumentación autoritaria, el puro sentido común o vulgaridad, como él lo llama, no pueden conducir a la verdad que requiere de un método.

En este sentido, la crítica, como desengaño de errores es el punto de partida metódico que comparte con Descartes, la pars destruens del nuevo método que propone de la siguiente manera: "Dar solución a una duda no puede ser si no es quitando los perjuicios [sic] sobre que estriba lo falso y manifestando la verdad que se oculta entre lo dudoso". 6

Como ya lo he señalado, ${ }^{7}$ me parece que en este texto se resume en forma sucinta la idea que del método tiene Sigüenza al poner de manifiesto un precepto crítico, un interés por el análisis y un criterio de verdad cercano a la evidencia cartesiana. Podemos por tanto considerar que varias ideas epistemológicas importantes, sobre todo en torno al método, parecen venir de Descartes, lo cual no es de extrañar puesto que le menciona de manera directa como filósofo moderno al lado de Gassendo y como el autor de la teoría sobre la tendencia centrífuga del movimiento de la materia:

Manifiesto es que la mancha nube o vapor viscoso $e$, conmovido de la arrebatadísima circungiración de la atmósfera solar, sale de ella por la tangente $\boldsymbol{e} h$ y forma el cometa $h$; y lo mismo de las manchas $d, g, f$, respecto de los otros cometas $i, k, l$, como a otro intento prueba bastantemente Renato Descartes en su filosofía. ${ }^{8}$

Aunque las menciones directas a Descartes no son muchas, lo que importa es que en ellas reconocemos que Sigüenza hizo una lectura detenida muy probablemente de los Principios de la filosofía del filósofo francés, puesto que $E l$ mundo o tratado de la luz se publicó tardíamente y que fácilmente don Carlos pudo haber hecho mención de "su filosofía" en lugar de sus Principios de la filosofía.

Pero tal vez, lo que más interesa, en este caso, es la aplicación que de la propuesta cartesiana del movimiento y las fuerzas tendenciales de la materia hace Sigüenza al servirse de ella para explicar, a su vez, el origen de los cometas.

Sí en efecto, no hay en Sigüenza una reflexión epistemológica sobre el método ni una referencia directa a Descartes sobre este asunto, no obstante, existen en La libra, párrafos de franca inspiración cartesiana como aquellos en que

${ }^{6}$ Ibid., p. 177 , núm. 379.

${ }^{7}$ Laura Benítez, La idea de historia en Carlos de Sigüenza y Góngora. México, Facultad de Filosofía y Letras, UNAM, 1982, p. 55 y ss.

${ }^{8}$ C. Sigüenza y Góngora, op. cit., p. 149. 
muestra la necesidad de combatir la duda y el prejuicio. Así, leemos en La libra:

Si probó lo que en él y los restantes quería [argumentos del padre Kino], no me toca a mí determinarlo sino a la Astronómica libra. Ella responderá por mí a quién, desnudándose primero de perjudicados afectos, se digne de preguntárselo. ${ }^{9}$

El método de la ciencia permite avanzar en la búsqueda del conocimiento sin "divertirse", sin caer en "paralogismos" y "pseudografías", pero sobre todo, sin recurrir al dogma:

[...] ni su reverencia, ni otro algún matemático, aunque sea el mismo Ptolomeo, pueden asentar dogmas en estas ciencias, porque en ellas no sirve de cosa alguna la autoridad sino las pruebas y la demostración $[\ldots]^{10}$

El método científico es eficaz cuando, por un lado, las dudas se ponen "[...] en la balanza de la razón”, se desvanecen las supercherías, los dogmas y los argumentos de autoridad y se refuerza la búsqueda científica con la observación apoyada en los instrumentos adecuados. ${ }^{11}$ También el uso del instrumental teórico (geometría, trigonometría y óptica) es en Sigüenza condición para el desarrollo de la nueva ciencia:

[...] habiendo tantos medios para ello como se hallan en los autores, y que cualquiera que no ignora la geometría, óptica y trigonometría, según lo pidieren las observaciones, puede discurrir, aplicar y resolver $[\ldots]^{12}$

En suma, con una base epistemológica cercana al cartesianismo, que alude constantemente a la "certeza" que no distingue pulcramente de "evidencia", Sigüenza, con los modernos astrónomos, nos dice que el método de la ciencia astronómica requiere de la observación y el cálculo, lo cual implica la doble fundamentación empírico-racional de esta compleja ciencia. Esta propuesta

9 Ibid., p. 150, núm. 312.

${ }^{10}$ Ibid., p. 123, núm. 252.

11 En La libra, p. 123, núm. 252, Sigüenza dice: "Advierto también que de observaciones hechas sin instrumento, sino con la vista y la estimación, es cosa indigna pensar que se puede concluir cosa alguna de consideración en materia tan primorosa como la que aquí se ventila".

12 Ibid., p. 121, núm. 249. 
que ya se encontraba en Galileo, le separa, hasta cierto punto del cartesianismo. En efecto, aunque Descartes hace expresa la importancia de la experiencia y de los fenómenos particulares para el avance y enriquecimiento de la ciencia, incluso para dirimir entre teorías alternativas en la explicación de fenómenos concretos, de ninguna manera aceptaría una doble fundamentación del conocimiento; en efecto, para él, el fundamento del conocimiento es racional aun cuando el origen pueda ser empírico (ideas adventicias) o racional (ideas innatas).

Una última cuestión en relación con la modernidad científica y filosófica de Sigüenza, se refiere al hecho de que intenta separar la verdad científica del dogma religioso. La idea no es, por supuesto, que Sigüenza postule, como algunos ilustrados lo harán después, que "la verdad" es la científica y no la religiosa, más bien, se trata de un deslinde de campos y objetos de conocimiento: en efecto, a "los doctores sagrados" y a "los santos padres" no les compete hablar de verdades científicas sino de verdades morales y religiosas. Así, en relación con el problema de los cometas Sigüenza comenta:

Pero llegados a los doctores sagrados y santos padres, ninguno pretendió asentarlo por dogma filosófico, sino valerse de estas apariencias [aparición de cometas en el cielo] como medios proporcionados para compungir el ánimo de los mortales y reducirlos al camino de la verdad. ${ }^{13}$

En una actitud, de igual reserva y cautela, Descartes, en el Discurso del método, refiere que siendo la teología algo que está por encima de la razón, nunca se propuso disputar sobre ello pues su razón finita sólo le permite ocuparse de las cuestiones naturales.

En ambos autores se percibe el intento por deslindar los campos de la fe y la razón para asegurarle al conocimiento científico un lugar independiente y no ancilar a la teología.

Finalmente, tanto Descartes como Sigüenza desconfían del "saber" astrológico ya por los "debilísimos" fundamentos sobre los que ha "levantado su fábrica" ${ }^{14}$ como, sobre todo, porque se erige sobre la suposición de cualidades ocultas e influjos misteriosos. El examen racional, de entrada, se opone a la magia y a la superstición. Descartes en el Discurso del método desecha la posibilidad de considerar a la astrología un conocimiento y Sigüenza, con su peculiar tono barroco, la califica de "principio de la ignorancia" y "origen de los infortunios" del hombre. ${ }^{15}$

13 Ibid., p. 14, núm. 20.

${ }^{14}$ Ibid., cap. "Manifiesto filosófico contra los cometas", p. 14, núm. 20. 
En suma:

[...] si la actitud crítica revela el alcance que la nueva forma de pensar tuvo sobre don Carlos, no es menos importante su idea del método. En efecto, sin volver la espalda al clima de la modernidad y sin duda conocedor de Gassendo, Descartes, Galileo, etcétera, Sigüenza maneja la idea de un método filosófico que permite despejar dudas y desechar errores a través del análisis que llevará a la mostración o manifestación de la verdad. ${ }^{16}$

Desde la perspectiva de la nueva ciencia, es posible ver en Sigüenza uno de estos autores que transita en la vía de reflexión epistemológica buscando la explicación del cosmos a través de su reducción racional por cuanto no acepta la distinción entre el mundo sublunar y supralunar, aunque sin el compromiso ontológico matemático de Descartes de la reducción de la materia a extensión. Además, se percibe claramente la constitución de este sujeto capaz de conocer al mundo mediante la aplicación del método. Desde luego, Sigüenza no recoge todas las propuestas cartesianas pero admite varios de sus principios epistemológicos y algunas de sus teorías. Así, don Carlos fue un científico moderno que aplicó el instrumental, tanto teórico como empírico a su alcance, al ámbito de los fenómenos celestes, que luchó críticamente contra el dogma autoritario, la superstición y el prejuicio y puso de manifiesto la necesidad de deslindar entre ciencia, por un lado y retórica, opinión infundada, autoridad y fe, por el otro.

\section{Descartes y la reflexión epistemológica de sor Juana Inés de la Cruz}

Juana de Asbaje y Ramírez de Santillana (1648-1695) es la mujer intelectual criolla más importante no sólo del siglo XVII sino probablemente de toda la época colonial.

Por "genio y figura" sor Juana puede ubicarse plenamente en el amplio marco de una cultura renacentista que no sólo la nutrió de aristotelismo y neoplatonismo sino que la hizo cultivar una fina actitud crítica.

Una de la más bellas piezas en que, por forma y contenido, se hace presente su filiación humanista, es su Respuesta a sor Filotea de la Cruz. En efecto, el estilo autobiográfico que se manifiesta en confesiones, meditaciones o diálogos, es expresión de una conciencia individualista propia de los autores del Renacimiento.

15 Ibid., p. 161, núm. 339.

${ }^{16}$ L. Benítez, op. cit., p. 70. 
Sor Juana, en tono de confidencia, reflexiona sobre sus intereses y preocupaciones intelectuales pero, sobre todo, sobre su concepción del conocimiento. Explica cómo existe una concatenación entre las diferentes ciencias, vínculo o relación que permite entender su conjunto como unidad armónica. ${ }^{17}$

Esta propuesta se encuentra en algunos platonistas florentinos como Ficino, pero también se acerca a la mathesis universalis de Descartes y, aún más, a su temprana formulación de una ciencia mirabilis como ciencia unificada.

Sor Juana no se contenta con mostrar su adhesión a la idea de un saber armonioso, engarzado por la sabiduría divina, sino que su más importante intento es justo acceder a ese saber. En el Primero sueño, vasto poema, complejo por el simbolismo, el estilo barroco y el entrecruce de diversas propuestas filosóficas, acordes con el espíritu sincrético de los autores renacentistas, la autora transita por la vía de reflexión epistemológica al llevar a cabo un examen crítico de los métodos mediante los cuales se consideraba, en la época, factible la adquisición del conocimiento.

Así, el Primero sueño plantea una doble problemática; en efecto, revela la aspiración al conocimiento con mayúsculas y, a la vez, va mostrando los diversos caminos o vías de acceso al mismo de los que ella tenía conocimiento. Es por ésta, y otras razones que referiré más adelante, que considero que el poema filosófico de sor Juana puede ubicarse en la vía de reflexión epistemológica.

De la aspiración al conocimiento

La aspiración de la "humana mente" es la Causa primera la cual "contiene infinita toda esencia". ${ }^{18}$ Aspira al ser supremo pero no en una perspectiva mística sino como la cúspide en la jerarquía de los entes, como el continente de todas las formas o esencias según la tradición platónica y neoplatónica. Pero la aspiración sólo es voluntad, sólo es querer, anhelo infinito que en el ser humano no equivale a una razón infinita.

Al paso que sor Juana deja un poco "balbuceando", para el caso de la máxima aspiración, el obstáculo que representa la evidente finitud de la razón humana, René Descartes, en sus Meditationes de prima philosophia establece con claridad, como parte de su teoría del error que, por ser el entendimiento finito, muchas veces, guiados sólo por nuestra volición, erramos al precipitarnos sin dar lugar a los juicios del entendimiento. ${ }^{19}$

Del conocimiento del mundo natural

${ }^{17}$ Juana Inés de la Cruz, "Respuesta a sor Filotea de la Cruz", en Florilegio, selec., pról. y notas de Elías Trabulse. México, Promexa, 1979, p. 742.

${ }^{18}$ J. I. de la Cruz, "Primero sueño", en op. cit., p. 416. 
Sin meterse en el problema de ¿por qué erramos?, sor Juana cambia de nivel pocos versos más abajo pues, de la aspiración al conocimiento de la totalidad de los entes, pasa al conocimiento del mundo natural. Ahora la "humana mente" se califica como "de lo sublunar reina soberana", porque tal vez ni con sus "intelectuales bellos ojos", pudo el alma ver o comprender la "quinta esencia" de las esferas celestes, sustancia sensible no perecedera que explicaba para Aristóteles la inmutabilidad de los cielos.

Así, el alma dirije su vista "libre de anteojos" a este mundo sublunar, de suyo un mundo de cambio y mudanza, pero que, por efecto del sueño, la estrategia metodológica de sor Juana, se encuentra dormido, en reposo, estático. Hace su aparición, en nuestra poetisa, el símil de los anteojos como sinónimo de prejuicio. Muy cercano a ella en tiempo y afecto, Carlos de Sigüenza también se había referido al prejuicio usando la mismo imagen, aunque él hablaba de que sus anteojos eran diáfanos. Pero tal vez esto adquiera aún mayor sentido si tomamos en cuenta que no sólo la imagen de los anteojos sino sobre todo, el rechazo de los prejuicios, aparece en Descartes como parte fundamental del precepto crítico. $^{20}$

La filosofía moderna exige esta mirada diáfana del intelecto. Francis Bacon especificó que los prejuicios no sólo se reciben sino que también pueden ser generados por un mal uso del intelecto. A lo primero Descartes le llamó prevención y, a lo segundo, precipitación, dos males que hay que evitar si lo que se busca es un conocimiento evidente. ${ }^{21}$

Sor Juana pone dos condiciones para llegar al conocimiento del mundo natural: que el alma se libre de prejuicios y que el mundo permanezca estático pues, haciendo abstracción del cambio, puede la poetisa acceder más fácilmente a la esencia de las cosas. La liberación, en su caso, tiene que ver con una cura neoplatónica donde el alma debe prescindir en lo posible del cuerpo que estando en reposo es calificado por la poetisa como "muerto a la vida y a la muerte vivo".22

${ }^{19}$ R. Descartes, "Les Méditations", en Oeuvres philosophiques, t. II, p. 463. Ahí Descartes dice: "[...] la voluntad siendo mucho más amplia y más extensa que el entendimiento, no la puedo contener en los mismos límites sino que la extiendo también a las cosas que no entiendo [...] y escoge [...] lo falso por lo verdadero".

${ }^{20}$ R. Descartes, "Règles pour la direction de l'esprit", en Oeuvres philosophiques, p. 150. "[...] cuando un hombre sufre de ictericia cree que todo es amarillo porque tiene el ojo impregnado de color amarillo [...] pero tal cosa no inducirá al error al entendimiento del sabio [...] quien no afirmará jamás que el mensaje se transmitió intacto y sin ninguna variación de las cosas externas a los sentidos [...]"

${ }^{21}$ R. Descartes, "Discours de la méthod", en Oeuvres philosophiques, t. I, p. 586. El precepto crítico establece: "[...] no recibir nada por verdadero que no conociera serlo evidentemente: es decir evitar cuidadosamente la precipitación y la prevención $[\ldots] "$ 
Con todo, el contacto del alma con el cuerpo no se pierde, aun cuando mínimo, a fin de liberar las potencias anímicas que alzan el vuelo hacia el conocimiento en la noche sosegada, sor Juana refiere que potencias como la percepción sensorial, la estimativa, la memoria y la fantasía requieren del alma y del cuerpo.

En una situación por completo diferente, puesto que rechaza el esquema aristotélico de la división del alma en vegetativa, motriz e intelectual, Descartes habla de las operaciones de la memoria y la percepción sensible como producto de la interacción alma-cuerpo, pues si en la Segunda meditación, sentir y recordar son pensamiento, una vez recuperado el cuerpo tiene que admitir niveles corpóreos de sensación y memoria y sobre todo operaciones intelectuales que se originan en datos sensibles. ${ }^{23}$

A pesar de que no se puede separar el alma del cuerpo, el intento de estos autores, en la vía de reflexión epistemológica, fue restringir el papel del cuerpo por temor de reducir el conocimiento a meras apariencias engañosas.

En sor Juana, no obstante que el alma se encuentra libre de prejuicios y que el mundo "sosegado [...] los átomos no mueve", ${ }^{24}$ la cantidad de los entes del mundo y la complejidad de cada uno, la hacen "retroceder cobarde". ${ }^{25}$

El mundo se torna "cúmulo incomprensible" pues conocer todas las esencias, si ya no de todos los objetos, al menos de cada género de ellos y hacer su análisis ontológico de acuerdo con las categorías establecidas por Aristóteles o bien apegándose a la jerarquía platónica de los entes, tan socorrida en el Renacimiento, no podía resultar una tarea abarcable por la mente humana.

En contraste, uno de los logros más importantes de la filosofía cartesiana fue precisamente reducir el "cúmulo incomprensible" a un universo físico plenamente inteligible y homogéneo, desde el punto de vista de su constitución, en tanto materia qua extensión. La reducción de esencias que lleva a cabo Descartes, le permite prescindir de la teoría de los géneros para quedarse con una sola forma o esencia del mundo físico: la extensión. ${ }^{26}$

Sor Juana está en el ámbito del mundo natural, desprejuiciada la mente, ubicada en una altura mayor que el monte Olimpo, sin obstáculos ni opacidades, extiende la vista a todo lo creado que, mediante el sueño, se encuentra estático, sosegado. Sin embargo, esta vista directa del alma no logra abarcar toda la

${ }^{22}$ J. I. de la Cruz, op. cit., p. 410.

${ }^{23}$ R. Descartes, "Résponses aux sixièmes objections", en Oeuvres philosophiques, t. II, p. 878. "Para comprender bien cuál es la certeza del sentido es necesario distinguir en él tres grados [...] El segundo contiene todo lo que resulta inmediatamente en el espíritu del hecho de que está unido al órgano corporal así movido y dispuesto por sus objetos".

${ }^{24}$ J. I. de la Cruz, "Primero sueño", en op. cit., p. 415.

${ }^{25}$ Ibid., p. 416. 
creación. Este método intuitivo que parecía, en principio posible, no se concreta en conocimiento. La mirada del intelecto se ve excedida por la cantidad de entes y la complejidad de cada uno.

En mi opinión no se trata del reconocimiento de los límites del sujeto sor Juana o de cualquier otro, para conocer el mundo natural con una mirada intuitiva, sino de poner de manifiesto que, semejante método, no puede entregarnos aquel conocimiento anhelado. Las lecciones del hermetismo renacentista no satisfacen a esta alma que ha hecho "cumbre de su propio vuelo" y "gozosa más suspensa, suspensa pero ufana" no halla sino que es "excedida de la grandeza de ellos [los objetos] su potencia". ${ }^{27}$

En este asunto Descartes no se da tan fácilmente por vencido. Desde joven persigue la scientia mirabilis, un saber unitario constituido a la luz del entendimiento. Espera con fe las señales para comenzar su empresa y una noche de 1619 junto a una estufa alemana recibe el esperado aviso. Siente en sueños cómo el espíritu de la verdad desciende para poseerlo. ${ }^{28}$ Pero aquí se rompe el tono hermético. Descartes luchará en adelante, más bien, por lograr la consolidación de una mathesis universalis cuya estructura sigue los pasos de las más fáciles demostraciones de los geómetras. Una ciencia en que todos los saberes están interconectados, desde sus sólidos fundamentos metafísicos, su robusto tronco físico y sus ramas: moral, artes mecánicas y medicina que han de darle la sabiduría y por ende la felicidad al hombre.

También la intuición juega en la filosofía cartesiana un papel importante pero se trata más bien, como él la describe, de una deducción en movimiento. ${ }^{29}$ De un habituarse de la razón a las formas de la deducción matemática y de lograr prescindir de la memoria a fin de recorrer, con una sola mirada del espíritu, toda la cadena deductiva.

Una intuición o mirada del intelecto pero ganada más en el terreno del cultivo de la razón, que en el de la adhesión volitiva que supone la ascensión del alma, como "llama ardiente" al cielo, en sor Juana.

De la intuición al método de ascenso y descenso

${ }^{26}$ R. Descartes, "Principles of Philosophy", en The Philosophical Writings of $D$

tes. Trad. de John Cottingham, Robert Stoothoff y Dugald Murdoch. Cambridge, Cambridge University Press, 1990, vol. I, p. 224. Descartes dice en el principio 4 de la parte 2: "Si hacemos ésto percibiremos que la naturaleza de la materia o cuerpo consiste, en general, no en ser algo que es duro o pesado o coloreado o que afecte los sentidos, en cualquier forma, sino simplemente en ser algo que es extenso en largo, ancho y profundidad".

${ }^{27}$ J. I. de la Cruz, "Primero sueño", en op. cit., p. 416.

${ }^{28}$ R. Descartes, "Olympiques" en Oeuvres philosophiques, t. I, p. 59. 
Pero Juana Inés no insiste en la intuición neoplatónica como método de conocimiento sino que ensaya una vía alternativa para conocer el mundo natural. Intenta seguir el Ars combinatoria de Atanasio Kircher que seguía, en buena medida, el método de ascenso y descenso del intelecto de Ramón Llull. Dicho sea entre paréntesis, cuando Beekman le prestó a Descartes el citado tratado, después de leerlo éste comentó que ése no era el tipo de método que a él le interesaba.

Para iniciar la nueva vía la poetisa reconoce que el alma debe separarse de la diversidad y regresar a sí misma. Así, procurará hacer a un lado el desorden reduciendo la diversidad a las categorías aristotélicas ${ }^{30}$ y luego irá ascendiendo, en la escala ontológica, gradualmente de los entes menos perfectos a los más perfectos.
[...] reparando, advertido, con el arte el defecto de no poder con un intuitivo conocer acto todo lo criado, sino que haciendo escala, de un concepto en otro va ascendiendo grado a grado, $[\ldots]^{31}$

Con todo, este método tampoco le permite conocer el todo del mundo natural a que el alma aspira. No conoce ni las especies ni los efectos tomados por separado, ni tampoco engarzados en una totalidad. Consternada declara que a veces sigue el método y a veces no, porque le parece un atrevimiento excesivo el tratar de conocerlo todo a

quien aún la más pequeña, aún la más fácil parte no entendía de los más manuales efectos naturales $^{32}$

De nueva cuenta no parece tanto que lo que se exhiba sean los límites de un sujeto concreto, Juana de Asbaje, para conocer el mundo natural, cuanto lo poco que se puede avanzar en este terreno con el método sincrético. La poetisa a veces encierra a los entes en las categorías aristotélicas pero ¿cómo entender

${ }^{29}$ R. Descartes, "Règles pour la direction de l'esprit", en Oeuvres philosophiques, t. I, p. 109. En la regla séptima Descartes recomienda ver cada término de la deducción en forma intuitiva pasando del uno al otro de tal modo que parezca que tenemos una intuición simultánea del todo.

${ }^{30}$ J. I. de la Cruz, "Primero sueño", en op. cit., pp. 419-420.

${ }^{31}$ Ibid., p. 420. 
con ello aún los más fáciles efectos naturales?

En suma, al igual que para Descartes, no es el Ars combinatoria lo que permitirá avanzar a nuestra joven estudiosa en el conocimiento de causas y efectos del mundo natural, por lo cual despierta del sueño, después de haber analizado críticamente los métodos que crearon en ella la expectativa de conocer todas las cosas. Métodos que el Renacimiento puso a su alcance y que se muestran insuficientes. Esto, sin embargo, no limita su aspiración al conocimiento, simplemente la pone en guardia contra vías inútiles. Así, más que de un escepticismo radical, se trata de un malestar o crisis que comparte con una buena cantidad de autores renacentistas que transitaron por la vía de reflexión epistemológica.

Descartes es uno de los representantes más conspicuos del pensamiento crítico y toma el camino de un escepticismo metodológico a fin de refutar el escepticismo radical. Se trata de dudar para no dudar, de hacer claro que los métodos heredados no son del todo útiles y que en el nuevo camino se arriesga todo conocimiento recibido, toda conocimiento sensible y aún toda verdad racional a fin de encontrar verdades indubitables, pues los más sencillos efectos de la naturaleza requieren explicaciones sólidamente fundadas en principios evidentes.

Naturalmente sor Juana no desarrolla toda un epistemología sobre un programa crítico, por haberlo hecho Descartes sigue siendo hoy el filósofo de Francia; pero sus avances, para una mujer en un convento en su época, la hacen una intelectual de aliento universal.

${ }^{32}$ Ibid., p. 424. 